\section{Translation elongation after assembly of ribosomes on the Cricket paralysis virus internal ribosomal entry site without initiation factors or initiator tRNA}

\author{
Tatyana V. Pestova ${ }^{1,2,3}$ and \\ Christopher U.T. Hellen ${ }^{1,4}$
}

\begin{abstract}
${ }^{1}$ Department of Microbiology, State University of New York Downstate Medical Center, Brooklyn, New York 11203, USA; ${ }^{2}$ A.N. Belozersky Institute of Physico-chemical Biology, Moscow State University, Moscow 119899, Russia
\end{abstract}

\begin{abstract}
Reconstitution of translation elongation from purified components confirmed that ribosomes that assembled on the Cricket paralysis virus intercistronic internal ribosomal entry site (IRES) without the involvement of initiation factors or initiator tRNA were active in elongation and are, therefore, true initiation complexes. The first elongation cycle occurred without peptide bond formation on $80 \mathrm{~S}$ ribosomes that did not contain tRNA in the $P$ site. It required elongation factors $1 \mathrm{~A}$ and 2 and $A$ site-cognate aminoacylated tRNA. Cycloheximide arrested ribosomes on the IRES only after two cycles of elongation, when the first deacylated tRNA reached the E-site after translocation from the A-site.
\end{abstract}

Received September 11, 2002; revised version accepted November 20, 2002.

Translation initiation on most eukaryotic mRNAs begins with binding of aminoacylated initiator tRNA (MettRNA $^{\text {Met }}$ i) in a complex with eukaryotic initiation factor (eIF) 2 and GTP to the 40S ribosomal subunit. The resulting complex binds to the capped $5^{\prime}$ end of mRNA and scans to the initiation codon (Dever 2002). eIF5 and eIF5B mediate displacement of factors from the 40S subunit and its joining with the 60S subunit, leaving MettRNA $^{\text {Met }}{ }_{i}$ in the P (peptidyl) site (Pestova et al. 2000). The resulting $80 \mathrm{~S}$ ribosome enters the elongation phase of translation.

Initiation on a few mRNAs is end independent and is, instead, mediated by an internal ribosomal entry site (IRES; Hellen and Sarnow 2001). Three distinct mechanisms for IRES-mediated initiation have been identified. The most remarkable of them is used by the intergenomic region IRESs in the RNA genomes of insect picorna-like viruses such as Cricket paralysis virus $(\mathrm{CrPV}$; Sasaki and Nakashima 1999, 2000; Domier et al. 2000;

[Keywords: Cricket paralysis virus; cycloheximide; eukaryotic elongation factor; internal ribosomal entry site; ribosome]

Corresponding authors.

${ }^{3}$ E-MAIL tatyana.pestova@downstate.edu; FAX (718) 270-2656.

${ }^{4}$ E-MAIL christopher.hellen@downstate.edu; FAX (718) 270-2656.

Article and publication are at http://www.genesdev.org/cgi/doi/10.1101/ gad.1040803.
Wilson et al. 2000a,b). These 200 nucleotide-long IRESs direct translation of the structural proteins encoded by the second open reading frame (ORF2). Their most unusual property is that initiation occurs at a non-AUG triplet and does not involve Met-tRNA ${ }^{\text {Met }}{ }_{i}$.

On the basis of biochemical analysis, a model for initiation on the CrPV IRES was proposed in which a $80 \mathrm{~S}$ ribosome assembles without the involvement of eIFs so that a base-paired triplet at the IRES' $3^{\prime}$-end is placed in the $P$ site, mimicking the AUG codon/Met-tRNA ${ }^{\text {Met }}{ }_{\mathrm{i}}$ anticodon interaction (Wilson et al. 2000a). In this model, the $80 \mathrm{~S}$ ribosome would begin to translate ORF2 after aminoacyl-tRNA has been brought to the ribosomal A (aminoacyl) site. This proposed initiation mechanism is exceptional, but the first elongation step (termed pseudotranslocation) would also be unusual because it occurs without tRNA in the P site and, thus, without prior peptide bond formation.

Some aspects of this model (such as the lack of requirement for eIF2/GTP/Met-tRNA ${ }^{\text {Met }}{ }_{i}$ ) have been corroborated by experiments in which levels of Met-tRNA ${ }^{\mathrm{Met}}{ }_{\mathrm{i}}$ or active eIF2 were reduced (Wilson et al. 2000a; Thompson et al. 2001). However, neither the requirements for other eIFs, nor how the elongation process is initiated have been determined. We report here that we have reconstituted the initial cycles of elongation in vitro using purified components to address these questions. Our results constitute direct proof for all principal elements of the previously proposed model and show, for the first time, that ribosomes can begin elongation on a natural mRNA after initiation without initiator tRNA or initiation factors.

\section{Results and Discussion}

\section{Purification of elongation factors}

Elongation factors required for translocation of ribosomes assembled in vitro on the IRES from purified 40S and $60 \mathrm{~S}$ subunits in the absence of eIFs were purified from rabbit reticulocyte lysate (RRL). eEF2 was purified to apparent homogeneity (Fig. 1C). Western blotting with commercially available antibodies was used to confirm eEF2's identity and to monitor purification of eEF1A. After gel filtration on Superdex G200, eEF1A eluted either as a single $48-\mathrm{kD}$ protein or as high molecular weight complexes with two or three other polypeptides with molecular weights of 50,31 , and $25 \mathrm{kD}$ (Fig. 1a,b). eEF1A copurified with these polypeptides on subsequent MonoS ion-exchange chromatography. The identities of all four polypeptides were confirmed by LC-nanospray tandem mass spectrometry of peptides derived from them by in-gel tryptic digestion done at an inhouse facility. The $50-\mathrm{kD}$ polypeptide yielded the peptides ILGLLDAHLK, STFVLDEFKR, and EYFAWEGAFQHVGK that perfectly match amino acids $138-147,286-295$, and 415-428 of rabbit eEF1B $\gamma$. The $48-\mathrm{kD}$ polypeptide yielded peptides THINIVVIGHVDSGK, EHALLAYTL GVK, and LPLQDVYK that exactly match amino acids $6-20,135-146$, and $248-255$ of rabbit eEF1A. The $31-\mathrm{kD}$ polypeptide yielded a peptide FEEHVQSVDIAAFNK that perfectly matches amino acids 266-280 of rabbit eEF1B $\beta$. The $25-\mathrm{kD}$ polypeptide yielded a peptide SPAGLQVLN DYLADK that exactly matches amino acids 8-22 of rab- 


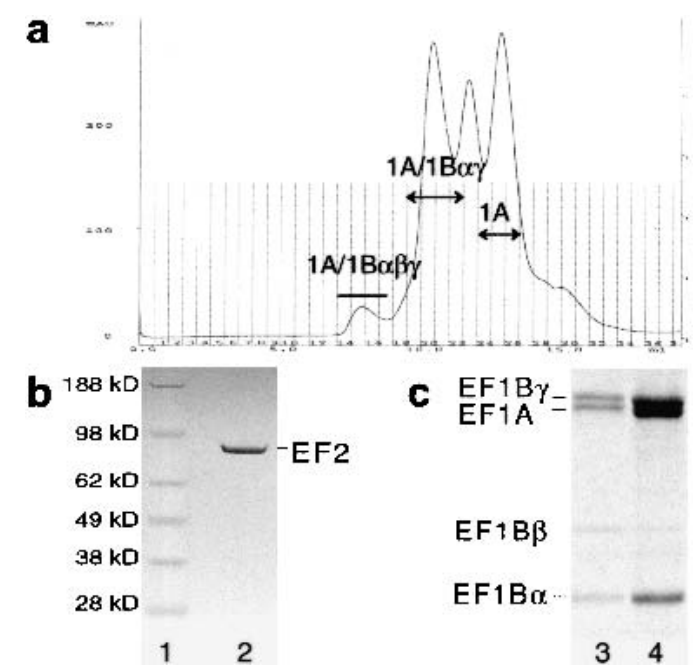

Figure 1. Purification of elongation factors. (a) Typical chromatogram of eEF1 on Superdex G200. The positions of eEF1A/1B $\alpha \beta \gamma$ (eEF1H), eEF1A/1B $\alpha \gamma$, and eEF1A are indicated. $(b, c)$ Resolution by SDS-PAGE of eEF2 (b, lane 2), eEF1A/1B $\alpha \beta \gamma(c$, lane 3), and eEF1A/ $1 \mathrm{~B} \alpha \gamma(c$, lane 4). The positions of molecular weight markers are indicated to the left of lane 1. Subunits of eEF1H are indicated to the left of lane 3. SDS-PAGE gels were stained with Coomassie blue.

bit eEF1B $\alpha$. All four polypeptides constitute the eEF1H complex, which consists of eEF1A and its guanine nucleotide exchange factor eEF1B. The lighter complex consists of eEF1A and $\mathrm{EEF} 1 \mathrm{~B} \alpha$ and $\gamma$ subunits.

Translocation of ribosomes assembled on the CrPV IRES

We used toeprinting to monitor elongation on the IRES. Stops due to $80 \mathrm{~S}$ ribosomes assembled on the IRES cor- respond to nucleotides $6228-6229$ (Fig. 2a, lane 2) rather than nucleotides 6226-6227, as we erroneously reported previously (Wilson et al. 2000a). These toeprints are $+15-$ 16 nucleotides from the first nucleotide $(+1)$ of the CCU triplet in the P site (and not $+13-14$ nucleotides, as reported previously), so that they are exactly analogous to stops due to $48 \mathrm{~S}$ and $80 \mathrm{~S}$ complexes assembled on the AUG start codon of other eukaryotic mRNAs (Anthony and Merrick 1992; Pestova et al. 1996, 1998a). Our previous error most likely occurred because loading buffer for toeprinting reactions had a higher formamide concentration than buffer for sequencing reactions. We regret any confusion that this error has caused. A consequence of this correction is that toeprints obtained in RRL in the presence of cycloheximide that were 6 nucleotides from the toeprints due to 80 S ribosomes assembled on the IRES, likely indicate ribosomal movement by two codons and represent not one but two elongation steps. The toeprint at nucleotide 6182 that appeared in the presence of 60S subunits has been noted previously (Wilson et al. 2000).

To reconstitute elongation on the IRES, we used 40S and $60 \mathrm{~S}$ subunits, purified elongation factors, and aminoacylated total cytoplasmic tRNA (¿aa-tRNA). In these experiments, toeprinting of preassembled complexes before and after addition of aa-tRNAs and eEFs confirmed that ribosomal movement began after assembly at the CCU triplet. To allow only one or two translocation events, total tRNA was aminoacylated with threonine and/or alanine. In the presence of $\Sigma$ aa-tRNA and both eEFs, $80 \mathrm{~S}$ ribosomes assembled on the IRES without eIFs could begin elongation (Fig. 2a, lane 5). However, instead of translocating for one or two codons, ribosomes yielded multiple toeprints further downstream, most strongly at positions that correspond to ribosomal arrest with a GAU codon in the A site. Commercial total tRNA is
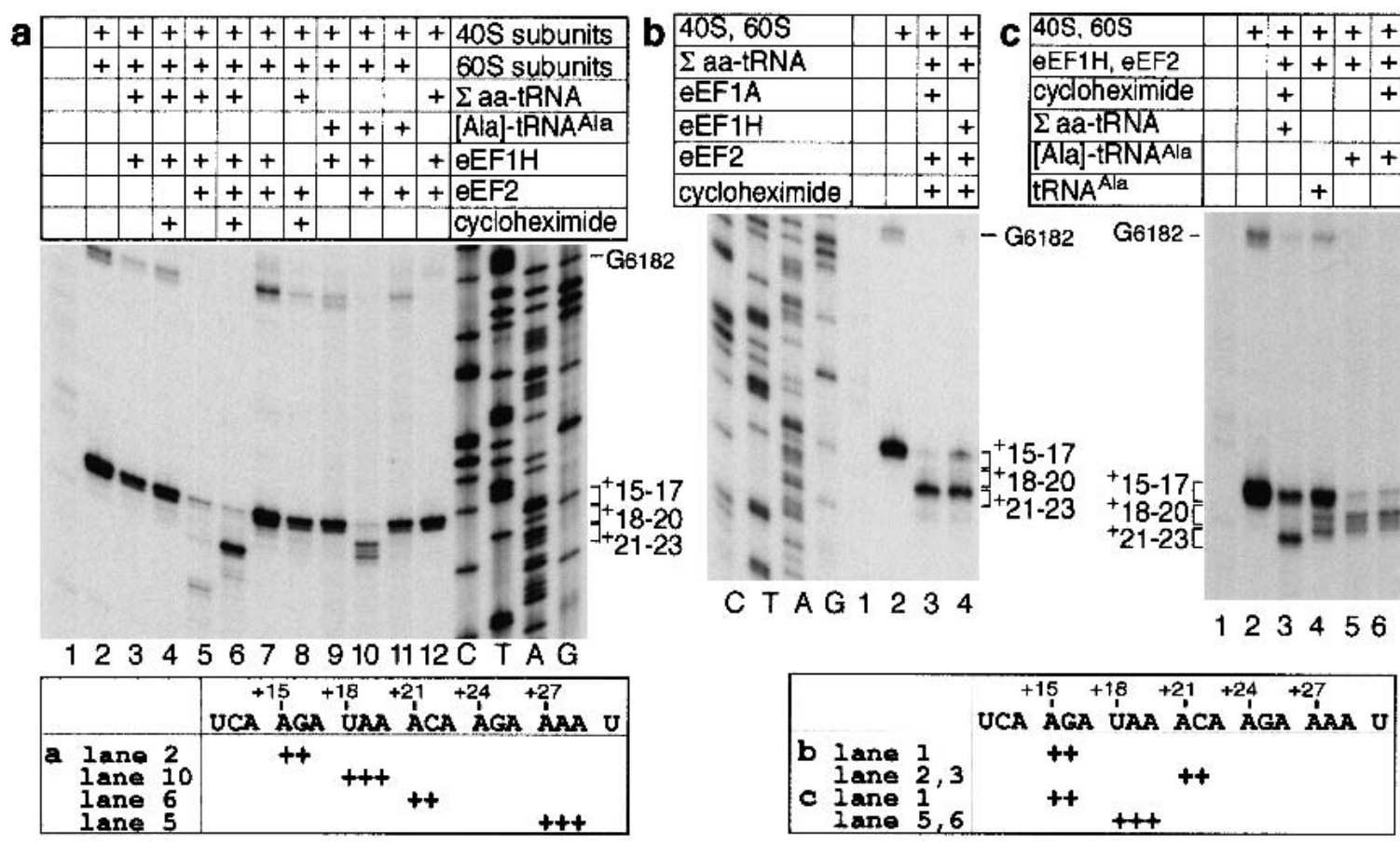

Figure 2. Elongation factor and tRNA requirements for translocation of ribosomes assembled on the IRES in the presence of the indicated components. The positions of toeprints relative to nucleotides +1 of the CCU triplet present in the P site before translocation are indicated to the right of each panel and schematically below the CrPV ORF2 sequence. Lanes $C, T, A$, and $G$ depict the CrPV sequence. 
therefore aminoacylated to a substantial extent, but contains relatively little of some aa-tRNAs. Incubation of total tRNA at alkaline $\mathrm{pH}$ did not deacylate it completely and prolonged incubation at higher $\mathrm{pH}$ inactivated it, probably by hydrolysis. For this reason, to monitor two elongation events, we included cycloheximide in the reconstituted system and obtained the same toeprints (Fig. 2a, lane 6) as previously in RRL with cycloheximide (Wilson et al. 2000a). Translocation required eEF2 (Fig. 2a, lanes 3,4), eEF1H (Fig. 2a, lane 8), ¿aatRNA (Fig. 2a, lane 7), and 60S subunits (Fig. 2a, lane 12). eEF1H could be replaced by this complex lacking eEF1B $\beta$ (not shown). In contrast to eEF1H, our purified eEF1A did not promote translocation on the IRES /data not shown). This could have been because the unusual elongation process on the IRES has a special requirement for eEF1B or because our eEF1A was inactive. Because eEF1A kindly provided by W. Merrick (Department of Biochemistry, Case Western Reserve University, Cleveland, $\mathrm{OH}$ ) was as active as eEF1H (Fig. 2b, lanes 3,4), the nucleotide exchange activity of eEF1B is not required for the initial translocation steps on the IRES. The instability of eEF1A in the absence of eEF1B has been documented extensively (e.g., see Crechet et al. 1986).

As we were unable to deacylate total tRNA completely and could monitor only two elongation cycles in the presence of cycloheximide, to investigate the first elongation cycle, we replaced $\Sigma$ aa-tRNA by synthetic Ala-tRNA ${ }^{\text {Ala }}$ to decode the first codon of ORF2. This led to translocation by +3 nucleotides in the presence and absence of cycloheximide (Fig. 2a, lane 10, 2c, lanes 5,6). This first translocation cycle also required both eEFs (Fig. 2a, lanes 9,11). This result indicates that the IRES doesn't induce self-translocation, as hypothesized earlier on the basis of cycloheximide's failure to inhibit the first translocation cycle (Wilson et al. 2000a). In fact, the first two translocation cycles are not inhibited by cycloheximide, but both require eEF2. Deacylated tRNA ${ }^{\text {Ala }}$ was also translocated from $\mathrm{A}$ to $\mathrm{P}$ sites at a lower level than aminoacylated Ala-tRNA ${ }^{\text {Ala }}$ (Fig. 2c, lanes 4,5). We did not examine this phenomenon further, but note that eEF1A can bind deacylated tRNA (Negrutskii and El'skaya, 1998), and that deacylated tRNA and even just a 15-nucleotide anticodon stem-loop can be translocated from A to $\mathrm{P}$ sites in prokaryotic ribosomes (Joseph and Noller 1998; Fredrick and Noller 2002).

\section{Inhibition of ribosomal translocation \\ by cycloheximide is template dependent}

The mechanism by which cycloheximide inhibits elongation is poorly understood, but is thought to involve inhibition of eEF2-dependent translocation of peptidyltRNA from A to P sites (Obrig et al. 1971). We reported previously that cycloheximide arrested ribosomes at the initiation codon of the encephalomyocarditis virus (EMCV) IRES, but permitted them to translocate from the CrPV start site in RRL (Wilson et al. 2000a). Therefore, we had concluded that the initial pseudotranslocation step on the IRES occurs in a mechanistically distinct manner from the first elongation step on conventional mRNAs and likely has different factor requirements. However, the present observations that the first two translocation events on the IRES have normal factor requirements (i.e., require eEF1A and eEF2A) led us to re-examine the influence of cycloheximide on ribosomal translocation.

We used native $\beta$-globin and synthetic (CAA)n-GUS mRNAs because they have different factor requirements, but both use the scanning mechanism for initiation (Pestova et al. 1998a; Pestova and Kolupaeva 2002), and the classical swine fever virus (CSFV) IRES, which initiates by a different mechanism than the EMCV IRES (Pestova et al. 1996, 1998b) to investigate cycloheximide's influence on translocation. Initiation on all of these mRNAs utilizes Met-tRNA ${ }^{\mathrm{Met}}{ }_{\mathrm{i}}$ and occurs at the $\mathrm{P}$ site. Unexpectedly, the effects of cycloheximide were template dependent. It arrested ribosomes at the CSFV AUG codon without permitting translocation (Fig. 3c), just as for EMCV. Cycloheximide arrested ribosomal movement on $\beta$-globin and (CAA)n-GUS mRNAs predominantly after +3 nucleotides (Fig. $3 a, b)$, which corresponds to a complete elongation cycle that results in translocation of the first deacylated (initiator) tRNA to the E site. Ribosomal movement was arrested on the CrPV IRES after two translocation events, which is also when the first deacylated tRNA (tRNA ${ }^{\text {Ala }}$ ) is translocated to the $\mathrm{E}$ site. The $\mathrm{E}$ site is filled by a domain of hepatitis C virus (HCV)-like IRESs such as CSFV before elongation begins (Spahn et al. 2001) and part of the EMCV IRES may play an analogous role. To account for these observations, we suggest that cycloheximide may block elongation by interacting with the E site when it contains deacylated tRNA (or a mimic thereof), preventing its release and thereby arresting further ribosomal translocation. The results of directed hydroxyl radical probing experiments indicate that part of the CrPV IRES occupies the E site (I.B. Lomakin, C.U.T. Hellen, and T.V. Pestova, in prep.), but the results of cycloheximide inhibition described here suggest that CrPV and HCVlike IRESs interact differently with the E site. The hypothesis that cycloheximide interacts with the E site is consistent with reports that it binds to the $60 \mathrm{~S}$ subunit, that its affinity is reduced by a mutation in ribosomal
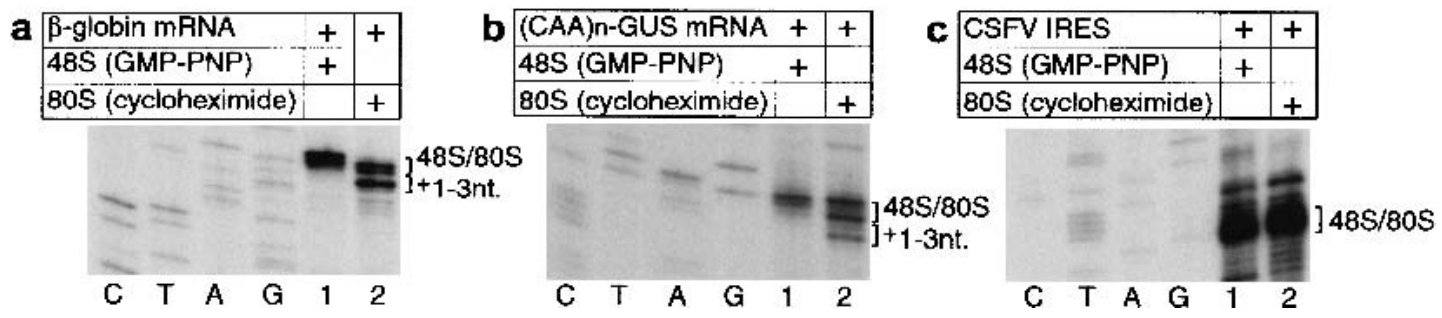

Figure 3. Template dependence of cycloheximide-mediated arrest of ribosomal translocation. Toeprints caused by arrested $48 \mathrm{~S}$ complexes and 80 S ribosomes on $\beta$-globin $(a)$, (CAA)n-GUS $(b)$, and CSFV $(c)$ IRES-NS' mRNAs in RRL in the presence of $1 \mathrm{mM}$ GMPPNP or $500 \mu \mathrm{gg} / \mathrm{mL}$ of cycloheximide, as indicated. The positions of toeprints relative to ntucleotides +1 of the start codon are indicated to the right of each panel. Appropriate cDNA sequences are on the left half of each panel. 
protein L29 (rpL29; Stöcklein and Piepersberg 1980), and that it prevents release of deacylated tRNA from ribosomes after translocation (Obrig et al. 1971). Substitutions in rpL29 and rpL41 confer cycloheximide resistance in many eukaryotes (Stöcklein et al. 1981; Yao and Yao 1991; Kawai et al. 1992; Stevens et al. 2001). Moreover, crystallographic analysis has shown that L44e, the Haloarcula marismortui homolog of rpL41 is in a position to interact directly with tRNA in the E site and that L15, the homolog of rpL29, is in an adjacent location (Ban et al. 2000; Yusupov et al. 2001).

\section{Translocation of ribosomes on different coding sequences}

Next, we wished to reconstitute the second and subsequent elongation events dependent on ribosomal loading on the IRES without including cycloheximide in reactions. There are experimental difficulties in preparing transcript tRNA ${ }^{\mathrm{Thr}}$ to decode the second codon in ORF2, so, instead, we used mRNAs comprising the IRES and heterologous coding sequences. We designed CrPV-MetPhe (CrPV-MF), CrPV-PhePheMet (CrPV-FFM), and CrPV-MetMetPhe (CrPV-MMF) mRNAs to monitor up to three elongation events and to assay the influence of cycloheximide. These IRES-proximal coding sequences consist of AUG (methionine) and UUC (phenylalanine) triplets so that they can be decoded by unmodified (i.e., transcript) Met-tRNA ${ }_{i}^{\text {Met }}{ }_{\text {(Åstrom et al. 1993) }}$ and by commercially available, relatively homogenous yeast tRNA $^{\text {Phe }}$, respectively. The use of aminoacylated $\left[{ }^{35} \mathrm{~S}\right]$ Met-tRNA ${ }^{\mathrm{Met}}{ }_{\mathrm{i}}$ facilitates analysis of peptide bond formation in a methionylpuromycin (MP) synthesis assay. These mRNAs all efficiently formed $80 S$ complexes that yielded toeprints 15-16 nucleotides from the CCU codon in the P site (Fig. 4a, lane 2, 4b, lane 3, 4c, lane 2).

In the presence of Phe-tRNA ${ }^{\text {Phe }}, \mathrm{eEF} 1 \mathrm{H}$, and eEF2, ribosomes translocated +6 nucleotides on CrPV-FFM
mRNA, yielding prominent $+21-23$-nucleotide toeprints (Fig. 4a, lane 3). Cycloheximide permitted translocation by 6 nucleotides, but reduced the prominence of the +23 nucleotide toeprint and enhanced the +21 -nucleotide toeprint (Fig. 4a, lane 4). Inclusion of Met-tRNA ${ }^{\text {Met }}{ }_{i}$ with Phe-tRNA ${ }^{\text {Phe }}$ in a reaction containing cycloheximide yielded a similar pattern of toeprints, which confirmed that cycloheximide permitted translocation by only 6 nucleotides (Fig. 4a, lane 6). However, inclusion of MettRNA $^{\text {Met }}{ }_{i}$ with Phe-tRNA ${ }^{\text {Phe }}$ in a reaction lacking cycloheximide yielded toeprints at +24-26 nucleotides, indicative of translocation forward by one triplet (Fig. 4a, lane 5); additional forward movement in this reaction likely reflects the presence of contaminating GlytRNA $^{\text {Gly }}$ in the Phe-tRNA ${ }^{\text {Phe }}$ preparation. In the presence of Met-tRNA ${ }^{\text {Met }}{ }_{i}$, eEF1H, and eEF2, ribosomes also translocated +6 nucleotides on CrPV-MMF mRNA, yielding strong toeprints at $+21-23$ nucleotides (Fig. 4b, lane 2). As with CrPV-FFM mRNA, cycloheximide also allowed two translocation steps on CrPV-MMF mRNA and reduced the prominence of the +23-nucleotide toeprint whether Phe-tRNA ${ }^{\text {Phe }}$ was present or not (Fig. $4 \mathrm{~b}$, lane 1; data not shown). Ribosomes incubated with eEF1H and eEF2 on CrPV-MF mRNA, as expected, translocated forward by one triplet in the presence of MettRNA ${ }^{\text {Met }}{ }_{\text {i }}$ (Fig. 4c, lane 3 ) and by two triplets in reactions containing Met-tRNA ${ }^{\text {Met }}{ }_{i}$ and Phe-tRNA ${ }^{\text {Phe }}$, either with or without cycloheximide, again giving a prominent toeprint at +21 nucleotides (Fig. 4c, lane 4; data not shown). However, translocation on this mRNA was less efficient than on others; a relatively high proportion of 80 S complexes did not move (Fig. 4c, lanes 3,4).

All three mutant mRNAs therefore supported tRNA, elongation factor, and codon-dependent translocation following binding of ribosomes to the IRES. The sequence downstream of the IRES is not a critical determinant of its function, although it can influence the efficiency of elongation without affecting $80 \mathrm{~S}$ complex

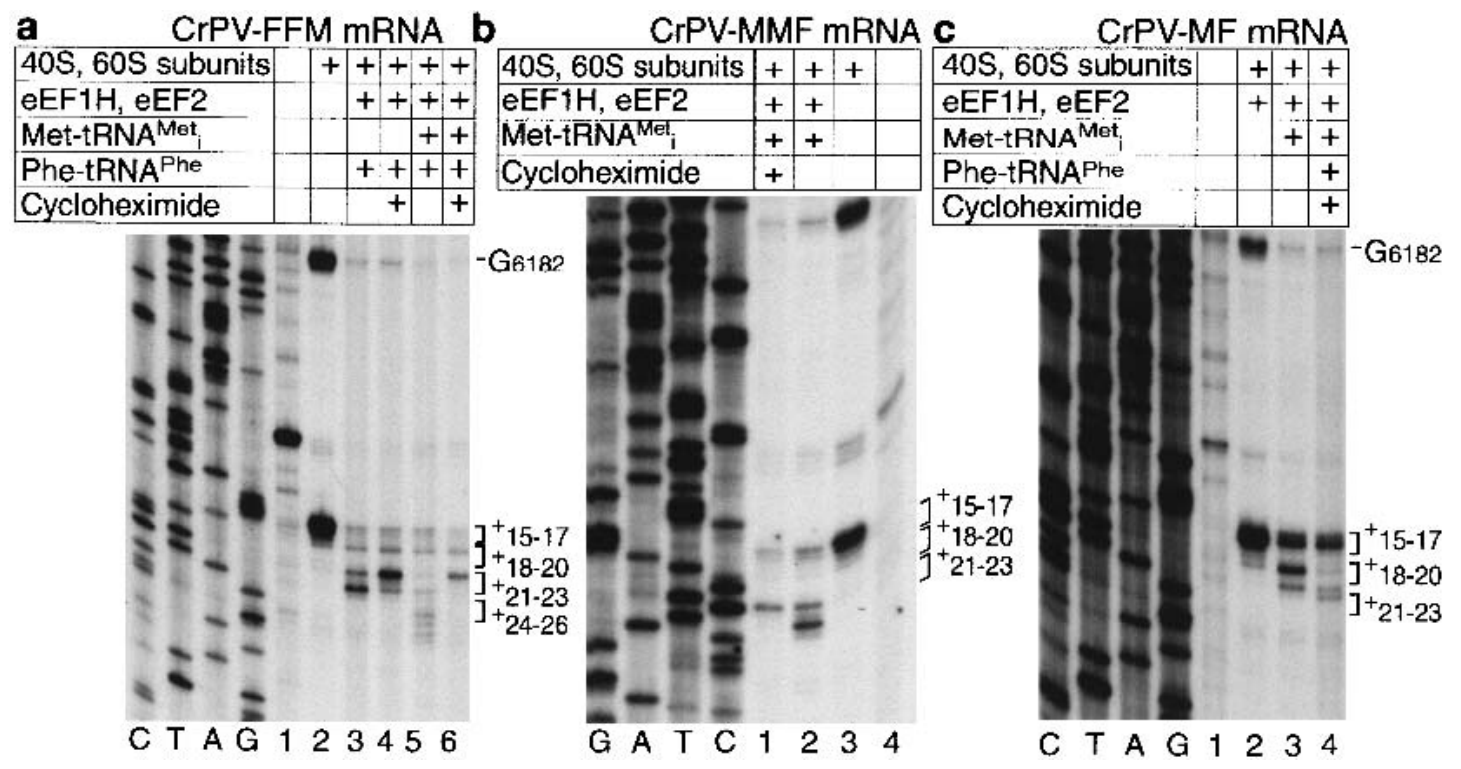

Figure 4. tRNA-dependent translocation of ribosomes assembled on the IRES. Toeprint analysis of translocation of ribosomes assembled on CrPV-FFM $(a)$, CrPV-MMF $(b)$, and CrPV-MF $(c)$ mRNAs in the presence of aminoacylated tRNAs and other components as indicated. The positions of toeprints relative to nucleotides +1 of the CCU triplet present in the $\mathrm{P}$ site before translocation are indicated to the right of each panel. Lanes $C, T, A$, and $G$ depict appropriate $C r P V$ mutant sequences. 
formation. Cycloheximide allowed +6-nucleotide translocation on mutant and wild-type mRNAs, so the unusual delay in arrest of translocation by cycloheximide is a property of the IRES and not the coding sequence.

\section{Participation of translocated peptidyl-tRNAs in peptide bond formation}

Toeprinting experiments revealed the translocation of ribosomes that had assembled on the IRES without eIFs. We used a MP synthesis assay to investigate whether translocation events correspond to productive steps in translation elongation. Puromycin binds in the A site and reacts with aminoacyl-tRNA in the P site, mimicking peptide bond formation in the peptidyltransferase center. MP synthesis was assayed on mutant mRNAs with ${ }^{35}$ S]Met-tRNA ${ }^{\text {Met }}{ }_{\text {in }}$ with or without Phe-tRNA ${ }^{\text {Phe }}$ (Fig. 5). All three mutants were active in MP synthesis, and as expected, unlike on CrPV-MF or CrPV-MMF mRNAs, MP synthesis on CrPV-FFM mRNA depended on the presence of Phe-tRNA ${ }^{\text {Phe }}$. This result confirms that initiation on the IRES does not require initiation factors. As could be expected on the basis of toeprinting data, MP synthesis was lowest on CrPV-MF mRNA. We do not know whether the higher yield of FFMP compared with MMP is indicative of a more efficient synthesis reaction on CrPV-FFM mRNA than on CrPV-MMF mRNA or of more complete solvent extraction of the radioactive product. We would like to emphasize that the CrPV IRES should be a useful model in biochemical investigation of translation elongation and termination on mRNA under physiological conditions. Initiation on this IRES requires only ribosomal subunits, and none of the complex set of factors required by other normal mRNAs and elongation itself has any special requirements, proceeding normally after the first two cycles.

In conclusion, these results confirm directly that protein synthesis on the CrPV IRES begins without any involvement of initiation factors or initiator tRNA. The $80 \mathrm{~S}$ ribosomes assemble with the 3 '-terminal CCU triplet of the IRES in the P site and proceed directly to the elongation phase after eEF1A has delivered cognate aminoacyl-tRNA to the A site. The initial elongation step also requires eEF2 to translocate aminoacyl-tRNA to the $\mathrm{P}$ site, but is in other respects unusual. Translocation

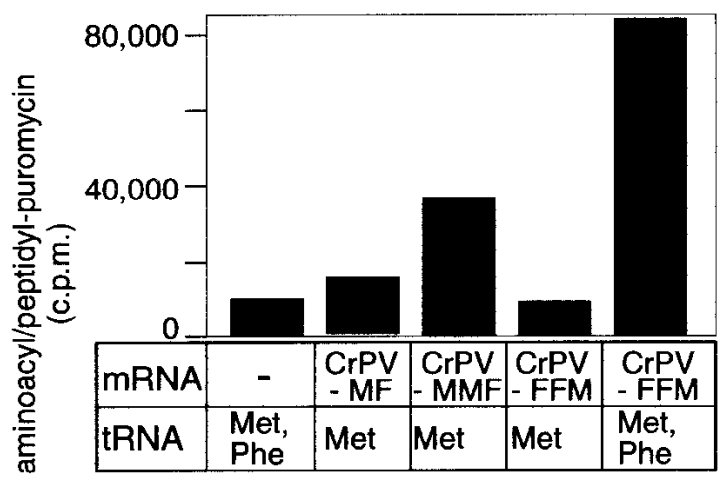

Figure 5. Template-dependent synthesis of $\left[{ }^{35} \mathrm{~S}\right]$ methionine-containing aminoacyl- or peptidylpuromycin by $80 \mathrm{~S}$ ribosomes assembled from 40S and 60S subunits on the CrPV IRES in the presence of eEFs $1 \mathrm{~A}$ and 2 with mRNAs and aminoacylated tRNAs as indicated. occurs without tRNA in the P site that can be translocated to the E site. The specific interaction of the acceptor stem of deacylated tRNA with the prokaryotic 50S subunit $\mathrm{E}$ site plays an essential role in ribosomal translocation catalyzed by EF-G (Noller et al. 2002). We therefore suggest that, in addition to elements that position it accurately on the $40 \mathrm{~S}$ subunit and that mimic the initiation codon/initiator tRNA anticodon, the IRES may also contain elements that function analogously to tRNA in interacting with the $60 \mathrm{~S}$ subunit $\mathrm{E}$ site to permit efficient eEF2-mediated translocation.

\section{Materials and methods}

Purification of factors and ribosomal subunits

eEF1A/1B complexes were purified from the ribosomal salt wash (RSW) $40 \%-50 \%$ ammonium sulfate (AS) precipitation fraction from RRL. It was applied in buffer A $(20 \mathrm{mM}$ Tris at $\mathrm{pH} 7.5,1 \mathrm{mM}$ DTT, $0.1 \mathrm{mM}$ EDTA, $10 \%$ glycerol) $+100 \mathrm{mM} \mathrm{KCl}$ to a DEAE cellulose column. The flow-through fraction was applied to a phosphocellulose column and fractionated by step elution. The eEF1A/1B complex was purified from the $250-\mathrm{mM} \mathrm{KCl}$ elution fraction by gel filtration on a FPLC Superdex G200 column. The eEF1A/1B complex lacking the $\beta$ subunit was further purified on a MonoS FPLC column (50-500 mM KCl gradient).

eEF2 was purified from the RSW $50 \%-70 \%$ AS precipitation fraction from RRL, which was applied in buffer $\mathrm{A}+100 \mathrm{mM} \mathrm{KCl}$ to a DEAE cellulose column and eluted with buffer $\mathrm{A}+100 \mathrm{mM} \mathrm{KCl}$, and then with buffer $\mathrm{A}+250 \mathrm{mM} \mathrm{KCl}$. The $250-\mathrm{mM} \mathrm{KCl}$ elution fraction was dialyzed against buffer $\mathrm{A}+100 \mathrm{mM} \mathrm{KCl}$, applied to a phosphocellulose column, and fractionated by step elution. The $250-\mathrm{mM} \mathrm{KCl}$ elution fraction was purified further on a MonoQ HR 5/5 FPLC column $(50-500 \mathrm{mM} \mathrm{KCl}$ gradient), yielding apparently homogenous eEF2.

Ribosomal subunits were purified as described (Pestova et al. 1998b).

Construction of plasmid DNA

Synthetic oligomers were inserted between the HindIII and BamHI sites of pBR322 to make ptRNA-Alal, which contains a T7 promoter next to the rabbit cytoplasmic tRNA ${ }^{\text {Ala }}$ gene (GenBank accession no. Y17041), followed by a BstNI site.

Vectors for transcription of the CrPV IRES and defined adjacent coding sequences were made by copying CrPV nucleotides 6023-6216 by PCR using the forward primer 5'-TATAAAGCTTAATATCGACTCACT ATAGGGAAAAAGCAAAAATGTGATCTTGCTTGTAAATACAATTT $\overline{T G A G A G}$-3' (in which the $\mathrm{T} 7$ promoter is underlined and CrPV sequences are italicized) and the reverse primers MMFGI, 5'-GTAGAG GATCCCGAACATCATAGGTAAATTTCTTAGGTTTTTCGACTACC-3'; FFMGI, 5'-GTAGAGGATCCCCATGAAGAAAGGTAAATTTCTTAG GTTTTTCGACTACC-3'; and MFGI, 5'-GTAGAGGATCCCGAACAT AGGTAAATTTCTTAGGTTTTTCGACTACC-3' (nucleotides complementary to CrPV sequences are italicized). PCR products were inserted between HindIII and BamHI sites in pBR322. For transcription, these plasmids were linearized with EagI. The resulting mRNAs comprise the IRES and a short heterologous coding sequence in frame with the tet ${ }^{\mathrm{r}}$ gene.

\section{Aminoacylation of $t R N A$}

Linearized pTRM1 and ptRNA-Alal were transcribed and purified (Pestova and Hellen 2001). Synthetic Ala-tRNA was refolded in the presence of $15 \mathrm{mM} \mathrm{Mg++}$ (Wolfson and Uhlenbeck 2002). Synthetic tRNAs were aminoacylated using rabbit aminoacyl-tRNA synthetases and purified (Pestova and Hellen 2001). Native unfractionated rabbit tRNA was from Novagen; native yeast phenylalanine tRNA was from Sigma.

Assembly and analysis of ribosomal complexes

Wild-type CrPV (Wilson et al. 2000a), mutant CrPV (described above), CSFV-NS' (Pestova et al. 1998b), and (CAA)n-GUS (Pestova and Kolupaeva 2002) mRNAs were transcribed in vitro. Native globin mRNA was from Invitrogen.

The $80 \mathrm{~S}$ complexes were preassembled by incubating $0.3 \mu \mathrm{g}$ of $\mathrm{CrPV}$ IRES mRNAs for $5 \mathrm{~min}$ at $37^{\circ} \mathrm{C}$ in $40-\mu \mathrm{L}$ reaction mixtures containing buffer B (20 nm Tris at pH 7.5, 100 mM KAc, 2 mM DTT, $2.5 \mathrm{mM} \mathrm{MgAc})$, 
$1 \mathrm{mM}$ ATP, $0.4 \mathrm{mM}$ GTP, $0.25 \mathrm{mM}$ spermidine, 5 pmole of $40 \mathrm{~S}$ subunits and 7 pmole of $60 \mathrm{~S}$ subunits. These complexes were then analyzed or mixed with combinations of 8 pmole of transcript Met-tRNA ${ }_{i}^{\text {Met }}$, 8 pmole of transcript Ala-tRNA ${ }^{\text {Ala }}, 12$ pmole of Phe-tRNA ${ }^{\text {Phe }}, 10 \mu \mathrm{g}$ of aminoacylated total cytoplasmic tRNA, $1 \mu \mathrm{g}$ of elongation factors, and $500 \mathrm{\mu g} / \mathrm{mL}$ of cycloheximide as indicated, and incubated for $5 \mathrm{~min}$ more at $37^{\circ} \mathrm{C}$.

Primer extension analysis of $80 \mathrm{~S}$ ribosomes was done using primers, reverse transcriptase, and $\left[\alpha-{ }^{32} \mathrm{P}\right] \mathrm{dATP}(\sim 6000 \mathrm{Ci} / \mathrm{mmole})$ as described (Pestova et al. 1998a,b; Wilson et al. 2000a; Pestova and Kolupaeva 2002). A primer 5'-GCGCTCATGAGCCCGAAGTGGCG-3' corresponding to pBR322 nucleotides 498-476 was used with mutant CrPV mRNAs. Translation in the presence of cycloheximide and primer extension in RRL were done as described (Wilson et al. 2000a).

Methionylpuromycin assays were done essentially as described (Pestova et al. 2000). Reaction mixtures $(40 \mu \mathrm{L})$ containing $1 \mu \mathrm{g}$ of CrPVIRES mRNA (as indicated), 5 pmole of $40 \mathrm{~S}$ subunits, 7 pmole of $60 \mathrm{~S}$ subunits, $1 \mu \mathrm{g}$ of eEF1H, $1 \mu \mathrm{g}$ of eEF2, 8 pmole of transcript $\left[{ }^{35} \mathrm{~S}\right]$ MettRNA $^{\text {Met }}{ }_{i}$ (spec. act. $40,000 \mathrm{cpm} / \mathrm{pmole}$ ), 12 pmole of Phe-tRNA ${ }^{\text {Phe }}$ (as indicated), and $1 \mathrm{mM}$ puromycin were incubated at $37^{\circ} \mathrm{C}$ in buffer $\mathrm{B}$.

\section{Acknowledgments}

This work was supported by NIAID grant AI51340. We thank W. Merrick for eEF1A and J. Calacay for sequencing eEF1H polypeptides.

The publication costs of this article were defrayed in part by payment of page charges. This article must therefore be hereby marked "advertisement" in accordance with 18 USC section 1734 solely to indicate this fact.

\section{References}

Anthony, D.D. and Merrick, W.C. 1992. Analysis of 48 S and 80 S complexes with mRNA as measured by sucrose density gradients and primer extension inhibition. J. Biol. Chem. 267: 1554-1562.

Åstrom, S.U., von Pawel-Rammingen, U., and Byström, A.S. 1993. The yeast initiator tRNA ${ }^{\text {Met }}$ can act as an elongator tRNA ${ }^{\text {Met }}$ in vivo. $J$. Mol. Biol. 233: 43-58.

Ban, N., Nissen, P., Hansen, J., Moore, P.B., and Steitz, T.A. 2000. The complete atomic structure of the large ribosomal subunit at $2.4 \AA$ resolution. Science 289: 905-920.

Crechet, J.B., Canceil, D., Bocchini, V., and Parmeggiani, A. 1986. Characterization of the elongation factors from calf brain. Eur. J. Biochem. 161: 635-645.

Dever, T.E. 2002. Gene-specific regulation by general translation factors. Cell 108: 545-556.

Domier, L.L., McCoppin, N.K., and D'Arcy, C.J. 2000. Sequence requirements for translation initiation of Rhopalosiphum padi virus ORF2. Virology 268: 264-271.

Fredrick, K. and Noller, H.F. 2002. Accurate translocation of mRNA by the ribosome requires a peptidyl group or its analog on the tRNA moving into the 30S P site. Mol. Cell 9: 1125-1131.

Hellen, C.U.T. and Sarnow, P. 2001. Internal ribosome entry sites in eukaryotic mRNA molecules. Genes \& Dev. 15: 1593-1612.

Joseph, S. and Noller, H.F. 1998. EF-G-catalyzed translocation of anticodon and stem-loop analogs of transfer RNA in the ribosome. EMBO $J$. 17: $3478-3483$

Kawai, S., Murao, S., Mochizuki, M., Shibuya, I., Yano, K., and Takagi, M. 1992. Drastic alteration of cycloheximide sensitivity by substitution of one amino acid in the L41 ribosomal protein of yeasts. $J$. Bacteriol, 174: 254-262.

Negrutskii, B.S. and El'skaya, A.V. 1998. Eukaryotic translation elongation factor $1 \alpha$ : Structure, expression, functions and possible role in aminoacyl-tRNA channeling. Prog. Nucl. Acids Res. Mol. Biol. 60: 47-78.

Noller, H.F., Yusupov, M.M., Yusupova, G.Z., Baucom, A., and Cate, J.H.D. 2002. Translocation of tRNA during protein synthesis. FEBS Lett. 514: 11-16.

Obrig, T.G., Culp, W.J., McKeehan, W.L., and Hardesty, B. 1971. The mechanism by which cycloheximide and related glutarimide antibiotics inhibit peptide synthesis on retiuclocyte ribosomes. J. Biol. Chem. 246: 174-181.

Pestova, T.V. and Hellen, C.U.T. 2001. Preparation and activity of syn- thetic unmodified mammalian $\mathrm{tRNA}_{\mathrm{i}}{ }^{\mathrm{Met}}$ in initiation of translation in vitro. RNA 7: 1496-1505.

Pestova T.V. and Kolupaeva, V.G. 2002. The roles of individual eukaryotic translation initiation factors in ribosomal scanning and initiation codon selection. Genes \& Dev. 16: 2906-2922.

Pestova, T.V., Hellen, C.U.T., and Shatsky, I.N. 1996. Canonical eukaryotic initiation factors determine initiation of translation by internal ribosomal entry. Mol. Cell. Biol. 16: 6859-6869.

Pestova, T.V., Borukhov, S.I., and Hellen, C.U.T. 1998a. Eukaryotic ribosomes require initiation factors 1 and $1 \mathrm{~A}$ to locate initiation codons. Nature 394: 854-859.

Pestova, T.V., Shatsky, I.N., Fletcher, S., Jackson, R.J., and Hellen, C.U.T. 1998b. A prokaryotic-like mode of binding of cytoplasmic eukaryotic ribosomes to the initiation codon during internal initiation of translation of Hepatitis C virus and classical swine fever virus RNAs. Genes \& Dev. 12: 67-83.

Pestova, T.V., Lomakin, I.B., Lee, J.H., Choi, S.K., Dever, T.E., and Hellen, C.U.T. 2000. The joining of ribosomal subunits in eukaryotes requires eIF5B. Nature 403: 332-335.

Sasaki, J. and Nakashima, N. 1999. Translation initiation at the CUU codon is mediated by the internal ribosome entry site of an insect picorna-like virus in vitro. J. Virol. 73: 1219-1226.

2000. Methionine-independent initiation of translation in the capsid region of an insect RNA virus. Proc. Natl. Acad. Sci. 97: 15121515.

Spahn, C.M.T., Kieft, J.S., Grassucci, R.A., Penczek, P., Zhou, K., Doudna, J.A., and Frank, J. 2001. Hepatitis C virus IRES RNA-induced changes in the conformation of the $40 \mathrm{~S}$ ribosomal subunit. Science 291: 1959-1962.

Stevens, D.R., Atteia, A., Franzén, L.G., and Purton, S. 2001. Cycloheximide resistance conferred by novel mutations in ribosomal protein L41 of Chlamydomonas reinhardtii. Mol. Gen. Genet. 264: 790-795.

Stöcklein, W. and Piepersberg, W. 1980. Binding of cycloheximide to ribosomes from wild-type and mutant strains of Saccharomyces cerevisiae. Antimicrob. Agents. Chemother. 18: 863-867.

Stöcklein, W., Piepersberg, W., and Böck, A. 1981. Amino acid replacements in ribosomal protein YL24 of Saccharomyces cerevisiae causing resistance to cycloheximide. FEBS Lett. 136: 265-268.

Thompson, S.R., Gulyas, K.D., and Sarnow, P. 2001. Internal initiation in Saccharomyces cerevisiae mediated by an initiator tRNA/eIF2-independent internal ribosome entry site element. Proc. Natl. Acad. Sci. 98: 12972-12977.

Wilson, J.E., Pestova, T.V., Hellen, C.U.T, and Sarnow, P. 2000a. Initiation of protein synthesis from the A site of the ribosome. Cell 102: $511-520$.

Wilson, J.E., Powell, M.J., Hoover, S.E., and Sarnow, P. 2000b. Naturally occurring dicistronic Cricket paralysis virus RNA is regulated by two internal ribosome entry sites. Mol. Cell. Biol. 20: 4990-4999.

Wolfson, A.D. and Uhlenbeck, O.C. 2002. Modulation of tRNA ${ }^{\text {Ala }}$ identity by inorganic pyrophosphatase. Proc. Nat1. Acad. Sci. 99: 59655970.

Yao, M.-C. and Yao, C.-H. 1991. Transformation of Tetrahymena to cycloheximide resistance with a ribosomal protein gene through sequence replacement. Proc. Natl. Acad. Sci. 88: 9493-9497.

Yusupov, M.M., Yusupova, G.Z., Baucom, A., Lieberman, K., Earnest, T.N., Cate, J.H.D., and Noller, H.F. 2001. Crystal structure of the ribosome at 5.5Å resolution. Science 292: 883-896. 


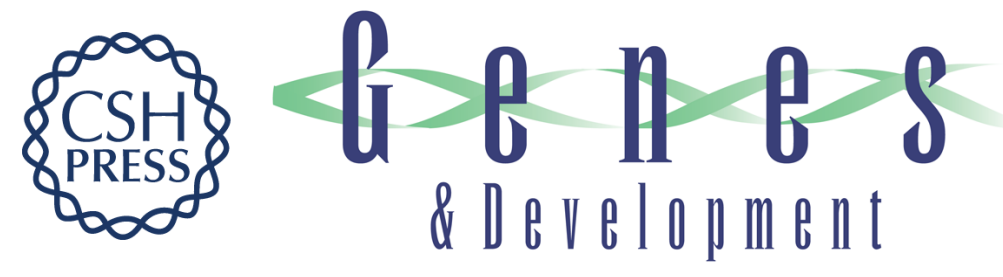

\section{Translation elongation after assembly of ribosomes on the Cricket paralysis virus internal ribosomal entry site without initiation factors or initiator tRNA}

Tatyana V. Pestova and Christopher U.T. Hellen

Genes Dev. 2003, 17:

Access the most recent version at doi:10.1101/gad.1040803

$\begin{array}{ll}\text { References } & \begin{array}{l}\text { This article cites } 31 \text { articles, } 19 \text { of which can be accessed free at: } \\ \text { http://genesdev.cshlp.org/content/17/2/181.full.html\#ref-list-1 }\end{array}\end{array}$

License

Email Alerting Receive free email alerts when new articles cite this article - sign up in the box at the top Service right corner of the article or click here.

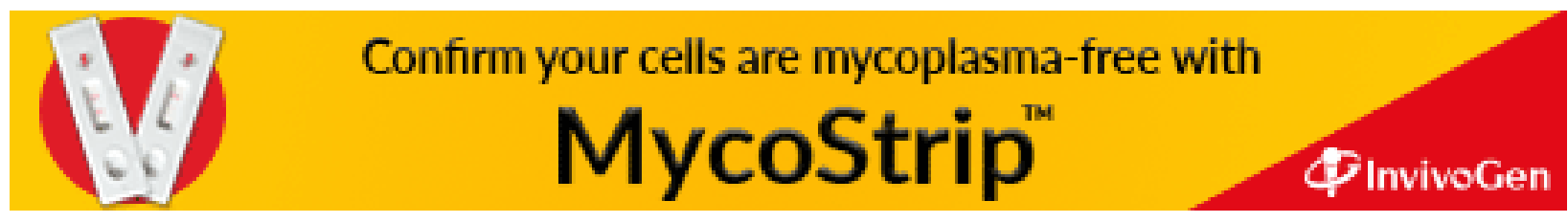

